\title{
Níveis de Lisina Digestível em Rações para Frangos de Corte de 22 a 42 Dias de Idade, Mantidos em Ambiente de Termoneutralidade ${ }^{1}$
}

\author{
Sandra Roselí Valerio Lana ${ }^{2}$, Rita Flávia Miranda de Oliveira ${ }^{3}$, Juarez Lopes Donzele ${ }^{3}$, \\ Paulo Cézar Gomes ${ }^{3}$, Roberta Gomes Marçal Vieira Vaz ${ }^{4}$, Wilkson de Oliveira Rezende ${ }^{5}$
}

RESUMO - Dois ensaios foram conduzidos para se avaliarem os efeitos de níveis de lisina digestível em rações, mantendo ou não a relação aminoacídica, sobre o desempenho de frangos de corte dos 22 aos 42 dias, criados em ambiente de termomeutralidade. No ensaio 1, foram utilizados 210 frangos de corte machos Avian Farms com peso inicial médio de 662,5 g e, no ensaio 2, 168 frangos com peso inicial médio de 623,7 g. Em ambos os ensaios, o delineamento experimental foi o inteiramente casualizado; no ensaio 1, as aves foram distribuídas em cinco tratamentos (níveis de lisina digestível em rações convencionais) e seis repetições, com sete aves cada e, no ensaio 2, em quatro tratamentos (níveis de lisina em rações mantendo a relação aminoacídica) e seis repetições, com sete aves cada. Nos ensaios 1 e 2, os níveis de lisina digestível da ração influenciaram de forma linear crescente o ganho de peso e a conversão alimentar. No ensaio 1 , observou-se efeito linear crescente dos tratamentos sobre o peso absoluto da carcaça. Não foi observado efeito dos tratamentos sobre o peso relativo da carcaça e os pesos absoluto e relativo de cortes nobres e de gordura abdominal. No ensaio 2, os pesos absoluto e relativo do peito e da coxa aumentaram linearmente, enquanto o peso absoluto da sobrecoxa elevou de forma quadrática até o nível de $0,955 \%$ de lisina. O peso relativo da sobrecoxa e os pesos absoluto e relativo da gordura abdominal não foram influenciados pelos tratamentos. Concluiu-se que frangos de corte machos Avian Farms na fase de 22 a 42 dias de idade, mantidos em ambiente de termomeutralidade, exigem no mínimo 1,015 e 1,075\% de lisina digestível na ração convencional e na ração mantendo a relação aminoacídica, respectivamente, correspondente a um consumo estimado de 28 g de lisina digestível.

Palavras-chave: conforto térmico, frango de corte, lisina digestível, proteína ideal

\section{Requirements of Dietary Digestible Lysine for Broilers from 22 to 42 Days Old on Thermoneutral Environment}

\begin{abstract}
Two trials were conducted to evaluate the effects of increasing dietary digestible lysine levels, maintaining or not the amino acid relation, on performance of broilers from 22 to 42 days old on thermoneutral environment. Two hundred and ten male broilers (averaging initial weight of $662.5 \mathrm{~g}$ ) and 168 broilers (averaging initial weight of $623.7 \mathrm{~g}$ ) were assigned to a completely randomized experimental design in trials 1 and 2, respectively. In trial 1, the broilers were allotted to five treatments (digestible lysine levels in conventional diets) and six replicates of seven broilers. In trial 2, the broilers were allotted to four treatments (digestible lysine levels in diet maintaining amino acid relation) and six replicates of seven broilers. In both trials, linear effect of digestible lysine levels on body weight gain and feed:gain ratio were observed. In trial 1, the increasing dietary digestible lysine levels increased linearly absolute carcass weight. There was no effect of lysine levels on relative carcass weights and on absolute and relative weichts of abdominal fat. In trial 2, absolute and relative breast and thigh weights increased linearly, while the absolute drumstick data increased quadraticly up to $0.955 \%$ digestible lysine level. No treatment effects on relative drumstick weight and absolute and relative weights of abdominal fat was observed. It was concluded that male broilers, Avian Farms, in the period from 22 to 42 days old, require at least 1.015 and $1.075 \%$ digestible lysine in conventional diet or in a diet maintaining the amino acid relation, respectively. This corresponds to an intake of $28 \mathrm{~g}$ digestible lysine for birds on a thermoneutral environment.
\end{abstract}

Key Words: broiler, thermoneutral environment, digestible lysine, ideal protein

\section{Introdução}

O progresso genético na taxa de crescimento, na conversão alimentar e no rendimento de carcaça é um desafio constante do ponto de vista nutricional. Uma vez que a expressão fenotípica do potencial genético depende do ambiente e da nutrição, é importante conhecer as exigências nutricionais das aves em processo de melhoramento, para se obter o máximo desempenho das mesmas.

A formulação de rações para aves com base na proteína bruta, envolvia perda de energia, principal-

\footnotetext{
1 Parte da tese de doutorado da primeira autora - Projeto financiado pela FAPEMIG.

2 Professora da UFAL.

3 Professor do DZO/UFV. E.mail: flavia@ufv.br; donzele@ufv.br

4 Estudante Pós-graduação DZO/UFV. E.mail: robertavaz@lycos.com

5 Secretaria de Agricultura - Cuiabá - MT.
} 
mente quando do excesso de aminoácidos na ração. Atualmente, com a disponibilidade de aminoácidos sintéticos a preços acessíveis, as rações passaram a ser formuladas com níveis de aminoácidos mais próximos das necessidades das aves, reduzindo o nível de proteína bruta das rações com a suplementação de aminoácidos sintéticos.

A lisina, apesar de ser o segundo aminoácido limitante, depois da metionina, na alimentação de aves, foi escolhida como aminoácido referência por ser utilizada, em seu metabolismo, quase que exclusivamente para deposição de proteína corporal (Pack, 1995). Han \& Baker (1994) obtiveram os níveis de 0,85\%, para máximo ganho de peso, e de $0,89 \%$ de lisina digestível, para melhor conversão alimentar de frangos de corte na fase de 21 a 42 dias de idade. Entretanto, recomendações de exigência de lisina em termos de lisina digestível são ainda escassas.

Avaliando os efeitos dos níveis de lisina digestível em rações, mantendo-se a relação entre a lisina e os demais aminoácidos essenciais para frangos no período de 22 a 42 dias de idade, Conhalato et al. (1999) constataram que o nível de 1,02\% de lisina digestível propiciou os melhores resultados de desempenho. Posteriormente, Costa et al. (1999) estimaram em 1,16 e $1,06 \%$ os níveis de lisina total e digestível, respectivamente, para frangos no período de 22 a 40 dias de idade. Posteriormente, Barboza et al. (2000) e Rostagno et al. (2000) demonstraram que os frangos no período de crescimento (22 a 42 dias de idade) exigem, respectivamente, 1,03 e 1,045\% de lisina total e digestível.

Realizou-se este trabalho para avaliar o efeito de níveis de lisina digestível em rações, mantendo-se ou não a relação aminoacídica, para frangos de corte machos de 22 a 42 dias de idade, mantidos em ambiente de termoneutralidade.

\section{Material e Métodos}

Os ensaios foram conduzidos no Laboratório de Bioclimatologia Animal do Departamento de Zootecnia do Centro de Ciências Agrárias da Universidade Federal de Viçosa, em Viçosa, MG.

Ensaio 1 - Níveis de lisina digestível em rações convencionais para frangos de corte de 22 a 42 dias de idade, criados em ambiente de termoneutralidade

Foram utilizados 210 frangos de corte machos Avian Farms, com peso inicial de 662,5 g \pm 4,6 g, mantidos em câmaras climáticas, com temperatura e umidade relativa controladas, segundo as recomendações do manual Avian Farms (Tabela 1) para esta categoria.

Durante o período inicial (1 a 21 dias de idade), as aves, mantidas em galpão convencional, foram alimentadas com ração com $3.000 \mathrm{kcal}$ de EM/kg e $21 \%$ de PB para satisfazer suas exigências nutricionais, segundo Rostagno et al. (1996) e manejadas conforme Lana (2000).

Aos 22 dias de idade, os frangos foram pesados e transferidos para as câmaras climáticas, quando se deu início ao período experimental. As aves foram alojadas em baterias com compartimentos de 0,85 x 0,85m, providos de comedouro e bebedouro tipo calha. As condições ambientais das salas foram monitoradas diariamente, duas vezes ao dia, por meio de termômetros de bulbos seco e úmido, de globo negro e de máxima e mínima, mantidos no centro das salas. O programa de luz adotado foi o contínuo (24 horas de luz artificial), durante todo período experimental, utilizando-se duas lâmpadas fluorescentes de 75 watts por sala. As aves foram distribuídas em delineamento inteiramente casualizado, com cinco tratamentos, seis repetições e sete aves por repetição.

Os tratamentos consistiram de uma ração basal (Tabela 2) à base de milho, farelo de soja e glúten de milho, formulada para atender as exigências das aves, segundo recomendações de Rostagno et al. (1996), exceto em lisina. A ração basal foi suplementada com L-lisina 99\% (0,00; 0,06; 0,12; 0,18 e 0,24) em substituição ao caulim, resultando em rações experimentais contendo 0,88 e 0,775\%; 0,94 e 0,835\%; 1,00 e

Tabela 1 - Condições ambientais observadas nas câmaras climáticas durante o período experimental, para frangos de corte de 22 a 42 dias de idade $^{1}$

Table 1 - Environmental conditions observed in the climatic chambers during the experimental period, for male broilers from 22 to 42 days old ${ }^{1}$

\begin{tabular}{lc}
\hline $\begin{array}{l}\text { Temperatura do ar }\left({ }^{\circ} \mathrm{C}\right) \\
\text { Average air temperature }\end{array}$ & $23,8 \pm 0,55$ \\
$\begin{array}{l}\text { Umidade relativa }(\%) \\
\text { Average relative humidity }\end{array}$ & $60,3 \pm 1,68$ \\
Temperatura de globo negro $\left({ }^{\circ} \mathrm{C}\right)$ & $24,0 \pm 0,60$ \\
$\begin{array}{l}\text { Average black globe temperature } \\
\text { Índice de temperatura de globo e umidade (ITGU) }\end{array}$ & $71 \pm 0,84$ \\
Black globe and humidity index (BHGI) &
\end{tabular}

${ }^{1}$ Valores médios (Average values). 
Tabela 2 - Composição percentual da ração basal Table 2 - Calculated (\%) composition of the basal diet

\begin{tabular}{|c|c|}
\hline Ingrediente (Ingredient) & $(\%)$ \\
\hline Milho (Corn) & 66,280 \\
\hline Farelo de soja (Soybean meal) & 21,204 \\
\hline Glúten de milho (Corn gluten) & 6,702 \\
\hline Fosfato bicálcico (Dicalcium phosphate) & 1,536 \\
\hline Calcário (Limestone) & 1,233 \\
\hline Óleo vegetal (Oil) & 1,240 \\
\hline Sal comum (Salt) & 0,415 \\
\hline Mistura vitamínica ${ }^{1}$ (Vitamin mix) & 0,050 \\
\hline Mistura mineral ${ }^{2}$ (Mineral mix) & 0,100 \\
\hline Anticoccidiano 3 & 0,050 \\
\hline $\mathrm{BHT}^{4}$ & 0,010 \\
\hline Cloreto de colina ${ }^{5}$ (Coline chloride) & 0,125 \\
\hline Stafac $^{6}$ & 0,055 \\
\hline Caulin & 0,844 \\
\hline L-lisina (99\%) (L-lysine) & 0,000 \\
\hline DL-metionina (99\%) (DL-methionine) & 0,154 \\
\hline L-triptofano (99\%) (L-tryptophan) & 0,002 \\
\hline \multicolumn{2}{|c|}{ Composição calculada (Calculated composition) } \\
\hline Proteína bruta (\%)(Crude protein) & 19,6 \\
\hline Energia metabolizável (kcal/kg) & 3.100 \\
\hline \multicolumn{2}{|l|}{ Metabolizable energy } \\
\hline Lisina total (\%)(Total lysine) & 0,880 \\
\hline Lisina digestível (\%)(Digestible lysine) & 0,775 \\
\hline Metionina+cistina digestível (\%) & 0,709 \\
\hline \multicolumn{2}{|l|}{ Digestible methionine + cystine } \\
\hline Triptofano digestível (\%) & 0,168 \\
\hline \multicolumn{2}{|l|}{ Digestible tryptophan } \\
\hline Cálcio (Calcium) (\%) & 0,920 \\
\hline Fósforo disponível (\%) & 0,390 \\
\hline \multicolumn{2}{|l|}{ Available phosphorous } \\
\hline Sódio (Sodium) (\%) & 0,200 \\
\hline \multicolumn{2}{|c|}{$\begin{array}{l}{ }^{1} \text { Conteúdo/kg (Content/kg): vit. A - } 15.000 .000 \mathrm{UI} \text {, vit. D3 - } 1.500 .000 \mathrm{UI} \text {, } \\
\text { vit. E - } 15.000 \mathrm{UI} \text {, vit. B1 - 2,0 g, vit. B2 - 4,0 g, vit. B6 - 3,0 g, vit. } \\
\text { B12 - 0,015 g, ácido nicotínico (nicotinic acid) - } 25 \mathrm{~g} \text {, ácido } \\
\text { pantotênico (pantothenic acid) - } 10 \mathrm{~g} \text {, vit. K3 - 3,0 g, ácido fólico } \\
\text { (folic acid) - } 1,0 \mathrm{~g} \text { bacitracina de zinco (zinc bacitracine) - } 10 \mathrm{~g} \text {, } \\
\text { selênio (selenium) - } 250 \mathrm{mg} \text {, antioxidante BHT (antioxidant BHT) - } \\
10 \mathrm{~g} \text { e veículo qsp (vehicle qsp) - } 1.000 \mathrm{~g} \text {. } \\
2 \text { Conteúdo/kg (Content/kg): manganês (manganese), } 80 \mathrm{~g} \text {; ferro } \\
\text { (iron), } 80 \mathrm{~g} \text {; zinco (zinc), } 50 \mathrm{~g} \text {; cobre (copper), } 10 \mathrm{~g} \text {; cobalto (cobalt), } \\
2 \mathrm{~g} \text {; iodo (iodine), } 1 \mathrm{~g} \text {; e veículo qsp (vehicle qsp) } 1000 \mathrm{~g} \text {. } \\
{ }^{3} \text { Salinomicina sódica (Sodic salinomicin) - } 60 \mathrm{ppm} \text {. } \\
{ }^{4} \text { Hidroxi-butil-tolueno. } \\
560 \% \text { de colina (60\% of choline). } \\
{ }^{6} \text { Virginiamicina } 2 \% \text { (Virginiamicin). }\end{array}$} \\
\hline
\end{tabular}

0,895\%; 1,06 e $0,955 \% ; 1,12$ e 1,015\% de lisina total e digestível, respectivamente. Os valores de aminoácidos totais dos ingredientes da ração experimental foram obtidos por meio de análises laboratoriais e, em seguida, foram corrigidos para aminoácidos digestíveis, utilizando-se os coeficientes de digestibilidade das tabelas Rhodimet-Rhône-Poulenc (1993) (Tabela 3). O fornecimento de ração e água foi ad libitum, trocando-se a água duas vezes ao dia.
Foram avaliados peso corporal, ganho de peso, consumo de ração e conversão alimentar. Adicionalmente, no final do período experimental (42ํㅡㄹa), após jejum alimentar de 12 horas, as aves foram pesadas e quatro aves de cada repetição, com peso médio de $\pm 10 \%$ em relação à média de repetição, foram abatidas. Após serem sangradas e depenadas, as aves foram evisceradas e as carcaças pesadas. Em seguida, a gordura abdominal foi retirada e pesada. Foram avaliados os pesos absoluto (g) e relativo (\%) das carcaças inteiras, dos cortes nobres (peito, coxa e sobrecoxa) e da gordura abdominal. Na determinação do rendimento de carcaça, foi considerado o peso da carcaça limpa em relação ao peso vivo após jejum. A gordura abdominal foi considerada como tecido adiposo em torno da cloaca, da Bursa de Fabricius e dos músculos abdominais adjacentes, conforme descrito por Smith (1993). O peso relativo dos cortes nobres foi calculado em relação ao peso da carcaça eviscerada.

As análises estatísticas das variáveis estudadas foram realizadas utilizando-se o programa SAEG (Sistema para Análises Estatísticas), desenvolvido na Universidade Federal de Viçosa - UFV (1999).

As estimativas de exigências de lisina digestível para frangos de corte de 22 a 42 dias de idade, em ambiente de termoneutralidade, foram estabelecidas com base nos resultados de desempenho, por meio de modelos de regressões linear, quadrática e/ou descontínuo “Linear Response Plateau” (LRP), conforme o melhor ajuste obtido para cada variável.

Ensaio 2 - Níveis de lisina digestível em rações, mantendo-se a relação aminoacídica, para frangos de corte de 22 a 42 dias de idade, criados em ambiente de termoneutralidade

Foram utilizados 168 frangos de corte machos Avian Farms, com peso inicial de 623,7 \pm 1,95 g. O ensaio foi realizado com aves de 22 a 42 dias de idade, mantidas em salas climatizadas com temperatura de $23,8 \pm 0,55^{\circ} \mathrm{C}$ e umidade relativa de $60,3 \pm 1,68 \%$.

Durante o período inicial (1 a 21 dias de idade), as aves foram criadas em galpão convencional, alimentadas com ração contendo 3.000 kcal de EM/kg e 21\% de PB para satisfazer suas exigências nutricionais, segundo Rostagno et al. (1996), e manejadas conforme Lana (2000).

Aos 22 dias de idade, os frangos foram pesados e transferidos para as câmaras climáticas, quando se 
Tabela 3 - Composição em aminoácidos totais e digestíveis dos ingredientes das rações Table 3 - Composition in total and digestible aminoacids of the diet ingredients

\begin{tabular}{|c|c|c|c|c|c|c|}
\hline \multirow[t]{2}{*}{$(\%)$} & \multicolumn{2}{|c|}{$\begin{array}{l}\text { Milho } \\
\text { Corn }\end{array}$} & \multicolumn{2}{|c|}{$\begin{array}{c}\text { Farelo de soja } \\
\text { Soybean meal }\end{array}$} & \multicolumn{2}{|c|}{$\begin{array}{c}\text { Glúten de milho } \\
\text { Corn gluten }\end{array}$} \\
\hline & $\begin{array}{l}\text { AAT }^{1} \\
\text { TAA }^{1}\end{array}$ & $\begin{array}{l}\mathrm{AAD}^{2} \\
\mathrm{DAA}^{2}\end{array}$ & $\begin{array}{l}\text { AAT }^{1} \\
\text { TAA }^{1}\end{array}$ & $\begin{array}{l}\mathrm{AAD}^{2} \\
\mathrm{DAA}^{2}\end{array}$ & $\begin{array}{l}\text { AAT }^{1} \\
\text { TAA }^{1}\end{array}$ & $\begin{array}{l}\mathrm{AAD}^{2} \\
\mathrm{DAA}^{2}\end{array}$ \\
\hline Lisina (Lysine) & 0,2730 & 0,2239 & 2,9634 & 2,6374 & 1,0558 & 1,0030 \\
\hline Metionina (Methionine) & 0,1588 & 0,1477 & 0,4300 & 0,3913 & 1,4552 & 1,3970 \\
\hline Met + cis (Meth + Cys) & 0,3213 & 0,2809 & 1,0404 & 0,9045 & 2,2027 & 2,0922 \\
\hline Arginina (Arginine) & 0,2919 & 0,2715 & 3,4906 & 3,2812 & 2,2243 & 2,2021 \\
\hline Valina (Valine) & 0,3749 & 0,3337 & 2,1104 & 1,8571 & 3,0156 & 2,9553 \\
\hline Glicina+Ser (Glycine+ser) & 0,6117 & 0,5312 & 4,4794 & 3,9525 & 4,6493 & 4,3833 \\
\hline Triptofano (Thryptophan) & 0,0628 & 0,0565 & 0,4354 & 0,3657 & 0,5370 & 0,5209 \\
\hline Leucina (Leucine) & 0,8913 & 0,8467 & 3,6415 & 3,2773 & 11,0267 & 10,8062 \\
\hline Proteína bruta (Crude protein) & \multicolumn{2}{|c|}{8,35} & \multicolumn{2}{|c|}{46,81} & \multicolumn{2}{|c|}{61,77} \\
\hline
\end{tabular}

${ }^{1}$ Aminoácido total, determinado pelo Laboratório da Guabi - Mogiana Alimentos - Campinas, SP (Total amino acid determined by Guabi Laboratory - Mogiana Feeds - Campinas, SP).

2 Aminoácido digestível, calculado pelo coeficiente de digestibilidade das tabelas Rhodimet... (1993) (Digestible amino acid calculated using digestibility coefficients of Rhodimet... tables (1993).

deu início ao período experimental. As aves foram alojadas em baterias com compartimentos de $0,85 \mathrm{x}$ $0,85 \mathrm{~m}$, providos de comedouro e bebedouro tipo calha. As condições ambientais das salas foram monitoradas diariamente, duas vezes ao dia, por meio de termômetros de bulbos seco e úmido, de globo negro e de máxima e mínima, mantidos no centro das salas. O programa de luz adotado foi o contínuo (24 horas de luz artificial) durante todo o período experimental, utilizando-se duas lâmpadas fluorescentes de 75 watts por sala. As aves foram distribuídas em delineamento experimental inteiramente casualizado, com quatro tratamentos, seis repetições e sete aves por repetição.

Os frangos receberam ração experimental (Tabela 4) à base de milho, farelo de soja e glúten de milho, segundo recomendações de Rostagno et al. (1996), suplementada com L-lisina 99\%, resultando em rações contendo 1,00 e $0,895 \%$; 1,06 e $0,955 \%$; 1,12 e $1,015 \% ; 1,18$ e $1,075 \%$ de lisina total e digestível, respectivamente. As concentrações dos aminoácidos DL-metionina, L-treonina, L-triptofano,
L-valina, L-isoleucina e L-arginina, em relação à lisina, foram mantidas em quantidades no mínimo suficientes para se obter o padrão de proteína ideal, conforme preconizado por Baker (1994), citado por Parsons \& Baker (1994), para aminoácidos digestíveis, em que a lisina equivale a $100 \%$, a metionina + cistina, a 75\%, a treonina, a 70\%, o triptofano, a $17 \%$, a valina, a $77 \%$, a isoleucina, a $67 \%$ e a arginina, a 105\%. Os valores dos aminoácidos totais dos ingredientes das rações experimentais foram obtidos por meio de análises laboratoriais, e, posteriormente, corrigidos para aminoácidos digestíveis, adotando-se os coeficientes de digestibilidade das tabelas Rhodimet-Rhône-Poulenc (1993) (Tabela 3). O fornecimento de ração e água foi ad libitum, trocando-se a água duas vezes ao dia.

Os procedimentos de monitoramento do ambiente e do fornecimento de ração, a determinação das medidas de desempenho e de rendimento de carcaça, a análise e o modelo estatístico foram os mesmos utilizados no ensaio 1. 
Tabela 4 - Composição percentual das rações experimentais

Table 4 - Composition (\%) of the experimental diets

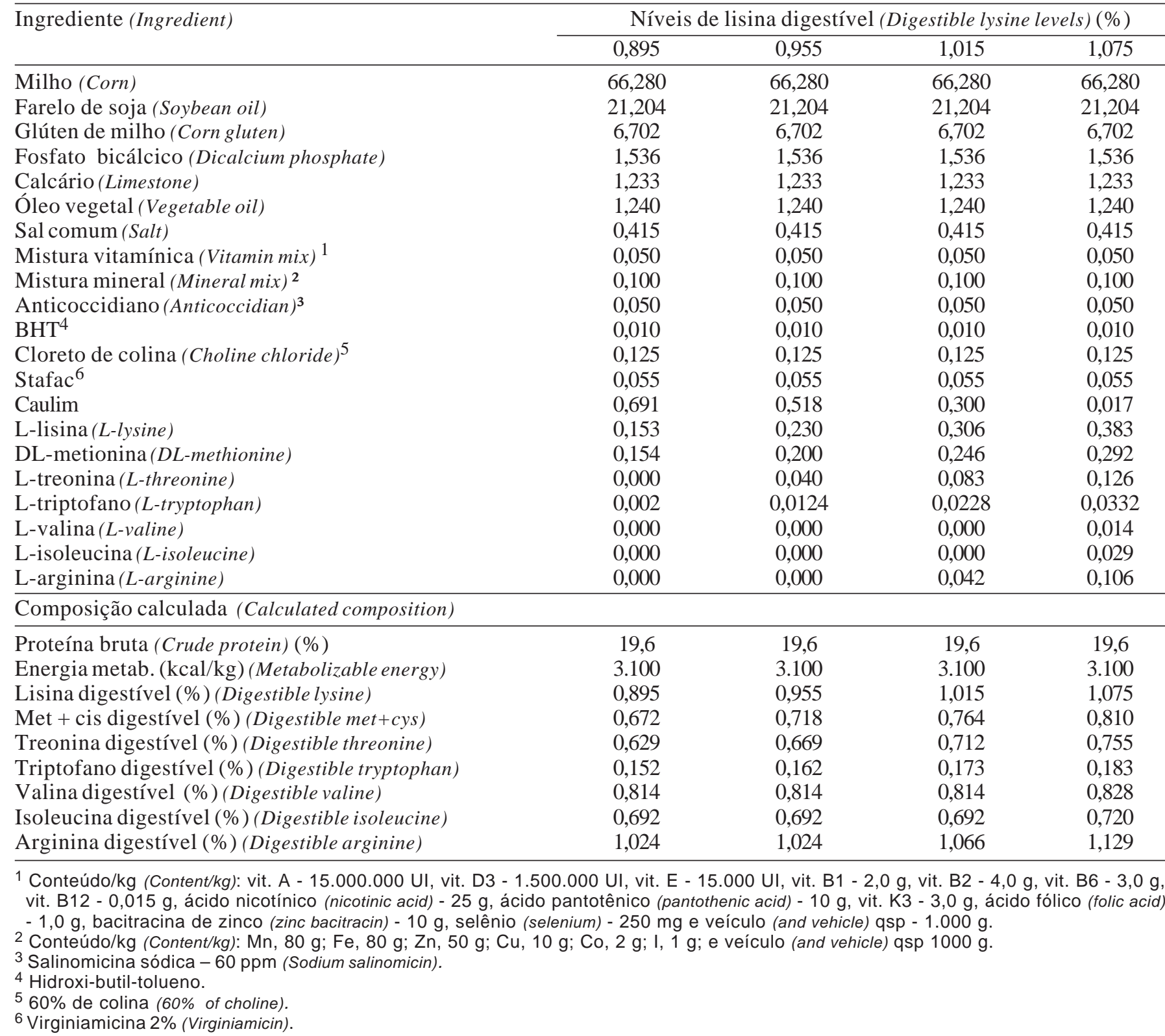

\section{Resultados e Discussão}

Na Tabela 5 são apresentados os resultados de desempenho e de consumo de lisina digestível dos frangos de corte alimentados com rações contendo diferentes níveis de lisina digestível, mantendo-se ou não a relação aminoacídica, no período de 22 a 42 dias de idade, mantidos em ambiente de termoneutralidade.

Constatou-se aumento linear $(\mathrm{P}<0,01)$ no peso final dos frangos aos 42 dias de idade, recebendo rações com diferentes níveis de lisina, mantendo-se ou não a relação aminoacídica, segundo as respectivas equações: $\hat{Y}=1341,30+643,890 X\left(r^{2}=0,89\right)$ e
$\hat{\mathrm{Y}}=1596,38+482,063 \mathrm{X}\left(\mathrm{r}^{2}=0,83\right)$. Melhoria linear no peso final das aves, em razão do aumento do nível de lisina da ração, também foi observada por Han \& Baker (1994). Em contrapartida, Conhalato et al. (1999), avaliando níveis de lisina para frangos de corte alimentados com rações convencionais, desconsiderando-se o conceito de proteína ideal, não verificaram variação significativa no peso final das aves.

Os níveis de lisina das rações, mantendo-se ou não a relação entre a lisina e os demais aminoácidos essenciais, considerados mais críticos para as aves, influenciaram $(\mathrm{P}<0,01)$ o ganho de peso dos frangos, que aumentou de forma linear de acordo com a 
Tabela 5 - Efeito dos níveis de lisina digestível na ração, mantendo-se ou não a relação aminoacídica, sobre o desempenho de frangos de corte no período de 22 a 42 dias de idade, mantidos em condições de termoneutralidade

Table 5 - Effect of dietary levels of digestible lysine, maintaining or not the amino acid relation, on performance of broilers from 22 to 42 days old on thermoneutral environment

\begin{tabular}{|c|c|c|c|c|c|c|c|c|c|c|c|}
\hline \multirow{3}{*}{$\begin{array}{l}\text { Variável } \\
\text { Variable }\end{array}$} & \multicolumn{11}{|c|}{ Níveis de lisina digestível (Digestible lysine levels) (\%) } \\
\hline & \multicolumn{6}{|c|}{$\begin{array}{l}\text { Ração convencional } \\
\text { Conventional diet }\end{array}$} & \multicolumn{5}{|c|}{$\begin{array}{l}\text { Ração mantendo-se a relação aminoacídica } \\
\text { Diet maintaining the amino acid relation }\end{array}$} \\
\hline & 0,775 & 0,835 & 0,895 & 0,955 & 1,015 & $\mathrm{CV}$ & 0,895 & 0,955 & 1,015 & 1,075 & $\mathrm{CV}$ \\
\hline $\begin{array}{l}\text { Peso corporal final }(\mathrm{g})^{1} \\
\text { Final body weight }^{1}\end{array}$ & 1974 & 1980 & 2035 & 2085 & 2065 & 2,96 & 1907 & 1979 & 1979 & 2036 & 2,30 \\
\hline $\begin{array}{l}\text { Ganho de peso }(\mathrm{g})^{1} \\
\text { Body weight gain }\end{array}$ & 1312 & 1320 & 1371 & 1421 & 1403 & 4,40 & 1283 & 1356 & 1355 & 1413 & 3,34 \\
\hline $\begin{array}{l}\text { Consumo de ração (g) } \\
\text { Feed intake }\end{array}$ & 2831 & 2780 & 2813 & 2876 & 2793 & 3,24 & 2502 & 2543 & 2563 & 2552 & 2,67 \\
\hline $\begin{array}{l}\text { Consumo lisina digestível (g) }{ }^{1} \\
\text { Digestible lisyne intake }^{1}\end{array}$ & 21,9 & 23,2 & 25,2 & 27,5 & 28,3 & 3,17 & 22,4 & 24,3 & 26,0 & 27,4 & 2,61 \\
\hline $\begin{array}{l}\text { Conversão alimentar }{ }^{1} \\
\text { Feed:gain ratio }{ }^{1}\end{array}$ & 2,16 & 2,11 & 2,05 & 2,02 & 1,99 & 2,72 & 1,95 & 1,88 & 1,89 & 1,81 & 2,70 \\
\hline $\begin{array}{l}\text { Eficiência de utilização de } \\
\text { Lisina para ganho de peso* } \\
\text { Eficiency of lysine utilization for }\end{array}$ & ight gai & 56,9 & 54,4 & 51,7 & 49,6 & & 57,3 & 55,8 & 52,1 & 51,6 & \\
\hline
\end{tabular}

1 Efeito linear $(P<0,01)$ (Linear effect, $P<0.01)$.

* Calculado como g de ganho de peso/g de lisina consumida (Calculated as g of weight gain/g of lysine intake).

equação: $\hat{Y}=711,310+650,324 X\left(r^{2}=0,89\right)$, quando se considerou a relação aminoacídica, e $\hat{\mathrm{Y}}=942,119$ $+472,897 X\left(r^{2}=0,85\right)$, quando se utilizou a ração convencional. Estes resultados corroboram aqueles obtidos por Holsheimer \& Ruesink (1993), Scheuermann et al. (1993) e Han \& Baker (1994). Conhalato et al. (1999), Costa et al. (1999) e Barboza et al. (2000). Por outro lado, Mendes et al. (1997) não observaram influência dos níveis crescentes de lisina sobre o ganho de peso dos frangos no período de 22 a 42 dias de idade, quando mantidos a $21,1^{\circ} \mathrm{C}$.

Embora o ganho de peso tenha aumentado de forma linear, foi constatado que, quando não se considerou a relação aminoacídica, o ganho de peso entre os dois maiores níveis de lisina (0,955 e 1,015\%) reduziu em $1,3 \%$, enquanto, ao se corrigir a relação entre a lisina e os demais aminoácidos essenciais, foi obtida melhor resposta com o maior nível de lisina avaliado, que correspondeu a 1,075 e 1,18\% de lisina digestível e total, respectivamente. Estes resultados indicam que a redução de 1,3\%, verificada no nível de 1,015\% de lisina digestível, no ganho de peso das aves que receberam a ração convencional, pode ter ocorrido em razão da limitação de um segundo aminoácido essencial.

O consumo de ração dos frangos não foi influenciado $(\mathrm{P}>0,05)$ pelos níveis de lisina avaliados, independentemente de ter sido mantida ou não a relação entre a lisina e os demais aminoácidos essenciais, considerados mais críticos para as aves. Estes resultados são semelhantes àqueles obtidos por Scheuermann et al. (1993) e Mendes et al. (1997). Por outro lado, divergem dos relatos de Conhalato et al. (1998), que verificaram variação significativa no consumo de ração dos frangos recebendo rações com diferentes níveis de lisina, mantendo-se a relação aminoacídica. Da mesma forma, os estudos realizados por Han \& Baker (1994), Conhalato et al. (1997), Knowles \& Southern (1998), Conhalato et al. (1999) e Costa et al. (1999) demonstraram variação no consumo de ração dos frangos à medida que se elevou os níveis de lisina da ração.

Os consumos semelhantes entre os diferentes níveis de lisina digestível avaliados, quando se considerou a relação aminoacídica, justificam-se pelo fato de as rações terem sido isoenergéticas e por a relação entre a lisina e os demais aminoácidos considerados mais críticos para as aves (metionina + cistina, treonina, triptofano, valina, isoleucina e arginina) ter sido mantida.

A variação não-significativa do consumo de ração dos frangos que receberam as rações convencionais, sem manter a relação aminoacídica, evidenciou que o desequilíbrio de aminoácidos, ocasionado pelas alterações nos níveis de lisina avaliados, não foi suficiente para influenciar negativamente este parâmetro. 
Tabela 6 - Valores de pesos absolutos e relativos da carcaça, dos cortes nobres e da gordura abdominal de frangos de corte aos 42 dias de idade, mantidos em condições de termoneutralidade, recebendo rações com diferentes níveis de lisina, mantendo-se ou não a relação aminoacídica

Table 6 - Values of carcass absolute and relative weights of noble cut and abdominal fat of broilers at 42 days old on thermoneutral environment fed diets with different lysine levels, maintaining or not the amino acid relation

\begin{tabular}{|c|c|c|c|c|c|c|c|c|c|c|c|}
\hline \multirow{3}{*}{$\begin{array}{l}\text { Variável } \\
\text { Variable }\end{array}$} & \multicolumn{11}{|c|}{ Níveis de lisina digestível (Digestible lysine levels) (\%) } \\
\hline & \multicolumn{6}{|c|}{$\begin{array}{l}\text { Ração convencional } \\
\text { Conventional diet }\end{array}$} & \multicolumn{5}{|c|}{$\begin{array}{l}\text { Ração mantendo-se a relação aminoacídica } \\
\text { Diet maintaining the amino acid relation } \\
\end{array}$} \\
\hline & 0,775 & 0,835 & 0,895 & 0,955 & 1,015 & $\mathrm{CV}$ & 0,895 & 0,955 & 1,015 & 1,075 & $\mathrm{CV}$ \\
\hline \multicolumn{12}{|l|}{$\begin{array}{l}\text { Peso absoluto (g) } \\
\text { Absolute weight }\end{array}$} \\
\hline Carcaça (Carcass) & $1581^{\mathrm{L} 1}$ & 1552 & 1617 & 1654 & 1665 & 3,57 & 1558 & 1595 & 1523 & 1570 & 6,76 \\
\hline Peito (Breast) & 423 & 453 & 457 & 438 & 465 & 6,99 & $421^{\mathrm{L} 2}$ & 450 & 446 & 466 & 7,54 \\
\hline Coxa(Thigh) & 214 & 215 & 204 & 216 & 217 & 6,77 & $197^{\mathrm{L} 2}$ & 202 & 205 & 210 & 5,29 \\
\hline Sobrecoxa (Drumstick) & 217 & 225 & 225 & 219 & 222 & 7,99 & $207^{Q}$ & 201 & 199 & 213 & 7,96 \\
\hline Gordura abdominal & 23,7 & 23,9 & 24,6 & 23,7 & 22,9 & 8,63 & 25,7 & 23,5 & 22,0 & 20,9 & 10,45 \\
\hline \multicolumn{12}{|l|}{ Abdominal fat } \\
\hline Relative weight & & & & & & \multicolumn{3}{|c|}{ Peso relativo (\%) } & & & \\
\hline Carcaça (Carcass) & 78,47 & 78,77 & 78,25 & 78,77 & 79,46 & 2,36 & 79,72 & 79,17 & 78,95 & 79,80 & 1,75 \\
\hline Peito (Breast) & 26,3 & 27,8 & 27,8 & 27,3 & 27,9 & 3,89 & $27,3^{\mathrm{L} 2}$ & 28,3 & 29,5 & 29,8 & 10,81 \\
\hline Coxa(Thigh) & 13,3 & 13,3 & 12,6 & 13,4 & 12,9 & 5,87 & $12,7 \mathrm{~L} 2$ & 12,7 & 13,6 & 13,4 & 8,16 \\
\hline Sobrecoxa (Drumstick) & 13,7 & 13,9 & 13,7 & 13,5 & 13,2 & 6,63 & 13,4 & 12,6 & 13,2 & 13,6 & 9,83 \\
\hline $\begin{array}{l}\text { Gordura abdominal } \\
\text { Abdominal fat }\end{array}$ & 1,47 & 1,78 & 1,52 & 1,46 & 1,37 & 8,31 & 1,65 & 1,42 & 1,46 & 1,34 & 14,28 \\
\hline
\end{tabular}

L1, L2 Efeito linear $(P<0,01)$ e $(P<0,05)$, respectivamente (Linear effect, $P<0.01$ and $P<0.05$, respectively).

$Q$ Efeito quadrático $(P<0,05)$ (Quadratic effect, $P<0.05)$.

Verificou-se efeito linear crescente $(\mathrm{P}<0,01)$ dos diferentes níveis de lisina sobre o consumo de lisina digestível dos frangos de corte aos 42 dias de idade que receberam as rações em que se manteve ou não a relação aminoacídica, de acordo com as equações: $\hat{\mathrm{Y}}=-2,61510+28,0710 \mathrm{X}\left(\mathrm{r}^{2}=0,99\right)$ e $\hat{\mathrm{Y}}=-0,236546+$ $28,4537 \mathrm{X}\left(\mathrm{r}^{2}=0,98\right)$, respectivamente, confirmando o resultado obtido por conhalato et al. (1999). Em contrapartida, Conhalato et al. (1998) não verificaram influência dos níveis de lisina da ração, mantendo-se a relação entre a lisina e os demais aminoácidos, sobre o consumo de lisina digestível dos frangos de corte dos 22 a 42 dias de idade.

Os níveis de lisina das diferentes rações influenciaram $(\mathrm{P}<0,01)$ de forma linear a conversão alimentar das aves, que reduziu de acordo com as equações: $\hat{\mathrm{Y}}=2,56884-0,697554 \mathrm{X}\left(\mathrm{r}^{2}=0,82\right)$, correspondente ao consumo estimado de 27,6 g de lisina digestível, quando se considerou a relação aminoacídica, e $\hat{\mathrm{Y}}=2,69142-0,696991 \mathrm{X}\left(\mathrm{r}^{2}=0,98\right)$, correspondente ao consumo estimado de 28,6 g de lisina digestível, quando se utilizou a ração convencional. Estes resultados corroboram aqueles obtidos por Moran Jr. \& Bilgili (1990), Scheuermann et al. (1993), Han \& Baker
(1994), Knowles \& Southern (1998), Conhalato et al. (1999), Costa et al. (1999) e Barboza et al. (2000), que também observaram variação na conversão alimentar, em função dos níveis de lisina da ração. Por outro lado, Mendes et al. (1997) não observaram melhoria na conversão alimentar dos frangos dos 22 aos 42 dias de idade em razão da variação nos níveis de lisina das rações.

Apesar da similaridade de resposta, constatou-se que, entre os três níveis de lisina comuns $(0,895,0,955$ e 1,015\% de lisina digestível) aos dois tipos de rações utilizadas, a conversão alimentar das aves que receberam a ração com correção da relação aminoacídica foi 4,9 a 9,1\% melhor. Como conseqüência desta diferença na conversão alimentar, a eficiência de utilização de lisina para ganho entre os três níveis de lisina comuns foi de 5,0 a 7,9\% maior para as aves que receberam a ração com a relação aminoacídica corrigida.

Os níveis de 1,075 e 1,015\% de lisina digestível, correspondentes a 1,18 e 1,12\% de lisina total, que proporcionaram os melhores valores de conversão alimentar das aves quando se considerou a relação entre lisina e demais aminoácidos essenciais e a ração convencional, respectivamente, estão acima daqueles 
Tabela 7 - Regressão de diferentes variáveis sobre os níveis de lisina digestível das rações Table 7 - Regression equations of different variables on dietary digestible lysine levels

\begin{tabular}{lll}
\hline Item (Item) & Regressão (Regression) & \\
\hline $\begin{array}{l}\text { Peso absoluto da carcaça* } \\
\text { Carcass absolute weight }\end{array}$ & $\hat{\mathrm{Y}}=912,375+785,000 \mathrm{X}$ & $\mathrm{r}^{2}=0,81$ \\
$\begin{array}{l}\text { Peso absoluto de peito** } \\
\begin{array}{l}\text { Peso absolute weight } \\
\text { Thigh absoluto de coxa** }\end{array}\end{array}$ & $\hat{\mathrm{Y}}=229,416+219,861 \mathrm{X}$ & $\mathrm{r}^{2}=0,84$ \\
$\begin{array}{l}\text { Peso absoluto de sobrecoxa** } \\
\text { Drumstick absolute weight }\end{array}$ & $\hat{\mathrm{Y}}=136,391+68,1944 \mathrm{X}$ & $\mathrm{r}^{2}=0,99$ \\
$\begin{array}{l}\text { Peso relativo de peito** } \\
\text { Breast relative weight }\end{array}$ & $\hat{\mathrm{Y}}=1535,93-2742,67 \mathrm{X}+1406,25 \mathrm{X}^{2}$ & $\mathrm{r}^{2}=0,96$ \\
$\begin{array}{l}\text { Peso relativo de coxa** } \\
\text { Thigh relative weight }\end{array}$ & $\hat{\mathrm{Y}}=14,5604+14,3574 \mathrm{X}$ & $\mathrm{r}^{2}=0,95$ \\
\hline
\end{tabular}

* Ração convencional (Conventional diet).

** Ração mantendo relação aminoacídica (Diet maintaining the aminoacidic relation).

de 0,85 e $0,815 \%$ de lisina digestível, recomendados por Han \& Baker (1994) e Emmert \& Baker (1997). No entanto, foram muito próximos ao nível de 1,045\% de lisina digestível, preconizado por Rostagno et al. (2000).

Os valores de peso absoluto e de rendimento da carcaça, pesos absolutos e relativos de cortes nobres e gordura abdominal obtidos, para os frangos de corte aos 42 dias de idade, mantidos em condições de termoneutralidade, são apresentados na Tabela 6 .

Com exceção do peso absoluto da carcaça, que aumentou $(\mathrm{P}<0,01)$ de forma linear (Tabela 7$)$, o peso relativo da carcaça e pesos absolutos e relativos dos cortes nobres e da gordura abdominal não variaram $(\mathrm{P}>0,05)$ entre os tratamentos quando se utilizou a ração convencional. Em contrapartida, quando se utilizou ração com correção do balanço aminoacídico, os pesos absolutos e relativos de peito e coxa aumentaram linearmente $(\mathrm{P}<0,05)$, enquanto o peso absoluto de sobrecoxa variou de forma quadrática $(\mathrm{P}<0,05)$, diminuindo até o nível de $0,955 \%$ de lisina (Tabela 7$)$. O peso relativo da sobrecoxa e os pesos absoluto e relativo de gordura abdominal não foram influenciados pelos tratamentos.

Os resultados de rendimento de carcaça obtidos estão coerentes com aqueles reportados por Conhalato et al. (1999), que também não encontraram variação no rendimento de carcaça dos frangos aos 42 dias recebendo rações com diferentes níveis de lisina, mantendo-se ou não o balanço aminoacídico, e confirmam o relato de Olomu \& Offiong (1980) de que o rendimento de carcaça é pouco influenciado pelos níveis nutricionais da ração.
Apesar de os resultados dos cortes nobres terem aumentado de forma linear, os maiores valores absolutos de peito e de coxa obtidos com a ração mantendo-se a relação aminoacídica foram similares aos maiores valores alcançados com a ração convencional. No entanto, ao se considerar o peso relativo, os valores de peito e de coxa dos frangos que receberam a ração em que se manteve a relação aminoacídica foram numericamente maiores que os observados nas aves alimentadas com a ração convencional nos níveis de lisina correspondentes, o que evidencia que a eficiência de utilização de lisina para ganho em peito e coxa, calculada como a razão entre o peso de peito ou de coxa (g) por g de lisina consumida, foi maior quando se utilizou a ração em que se manteve a relação aminoacídica nos três níveis de lisina correspondentes (0,895; 0,955 e 1,015\%).

Os ganho de peso e de peso absoluto de peito obtidos com a ração em que se considerou o balanço aminoacídico foram mais significativos que os alcançados com a ração convencional, não se observando variação no peso absoluto do peito, apesar do aumento linear no ganho de peso. De acordo com Sibbald \& Wolynetz (1986), a exigência de aminoácidos essenciais para máximo rendimento de carne de peito está acima daquela considerada adequada para crescimento.

Embora não tenha ocorrido diferença significativa entre os níveis de lisina digestível das diferentes rações, foi constatado que, quando se utilizou a ração em que se considerou o balanço aminoacídico, o peso absoluto da gordura abdominal reduziu gradativamente 
em até 18,17\% entre os tratamentos. Estes resultados estão coerentes com aqueles reportados por Han \& Baker (1994), Mendes et al. (1997) e Costa et al. (1999), que também observaram redução no conteúdo de gordura abdominal em razão do aumento do nível de lisina da ração. Esta redução no conteúdo de gordura abdominal pode ter resultado da menor disponibilidade de energia excedente para armazenamento, em razão do aumento no gasto de energia para deposição de carne na carcaça, evidenciado pelo aumento dos pesos absolutos do peito e da coxa destas aves.

\section{Conclusões}

Frangos de corte machos Avian Farms, no período de 22 a 42 dias de idade, mantidos em ambiente de termoneutralidade, exigem, no mínimo, 1,015 e 1,075\% de lisina digestível em ração convencional e em ração mantendo-se a relação aminoacídica, respectivamente, correspondente ao consumo estimado de $28 \mathrm{~g}$ de lisina digestível.

\section{Literatura Citada}

AVIAN FARMS. Broiler manual. In: http://www.avianfarms.com Avian Farms International, Inc., 1998, 34p.

BARBOZA, W.A.; ROSTAGNO, H.S.; ALBINO, L.F.T. et al. Níveis de lisina para frangos de corte de 22 a 40 e 42 a 48 dias de idade. Revista Brasileira de Zootecnia, v.29, p.1091-1097, 2000.

CONHALATO, G.S.; DONZELE, J.L.; ALBINO, L.F.T. et al. Níveis de lisina digestível para frangos de corte machos na fase de 22 a 42 dias de idade. Revista Brasileira de Zootecnia, v.28, p.98-104, 1999.

CONHALATO, G.S.; DONZELE, J.L.; FONTES, D.O. Níveis de lisina digestível para frangos de corte machos na fase de 22-42 dias de idade. In: REUNIÃO ANUAL DA SOCIEDADE BRASILEIRA DE ZOOTECNIA, 34., 1997, Juiz de Fora. Anais... Juiz de Fora: Sociedade Brasileira de Zootecnia, 1997. p.54.

CONHALATO, G.S.; DONZELE, J.L.; OLIVEIRA, R.F.M. et al. Níveis de lisina digestível mantendo a relação dos aminoácidos para frangos de corte machos na fase de 22 a 42 dias de idade. In: REUNIÃO ANUAL DA SOCIEDADE BRASILEIRA DE ZOOTECNIA, 35., 1998, Botucatu. Anais... Botucatu: Sociedade Brasileira de Zootecnia, 1998, p.282.

COSTA, F.G.P.; ROSTAGNO, H.S.; ALBINO, L.F.T. et al. Níveis dietéticos de lisina para frangos de corte, no período de 22 a 40 dias de idade In: CONFERÊNCIA APINCO DE CIÊNCIA E TECNOLOGIA AVÍCOLAS, 1999, Campinas. Anais... Campinas: Fundação Apinco de Ciência e Tecnologi Avícolas, 1999. p.18.

EMMERT, M.W.; BAKER, D.H. Use of the ideal protein concept for presicion formulation of amino acid levels in broilers diets. Journal of Applied Poultry Research, v.6, p.462-470, 1997.

HAN, Y.; BAKER, D.H. Digestible lysine requirements of male and female broiler chicks during the period three to six weeks posthatching. Poultry Science, v.73, p.1739-1745, 1994.
HOLSHEIMER, J.P.; RUESINK, E.W. Effect on performance, carcass composition, yield and financial return of dietary energy and lysine levels and finisher diets fed to broilers. Poultry Science, v.2, p.806-815, 1993.

KNOWLES, T.A.; SOUTHERN, L.L. The lysine requirement and ratio of total sulfur amino acids to lysine for chicks fed adequate or inadequate lysine. Poultry Science, v.77, p.564-569, 1998.

LANA, G.R.Q. Avicultura. 1.ed. Campinas: Livraria e Editora Rural Ltda, 2000. 268p.

MENDES, A.A.; WATKINS, J.A.; ENGLAND, E.A. et al. Influence of dietary lysine levels and arginine:lysine ratios on performance of broilers exposed to heat or cold stress during the period of three to six weeks of age. Poultry Science, v.6, p.472-481, 1997.

MORAN JR., E.T.; BILGILI, S.F. Processing losses, carcass quality and meat yield of broiler chickens as influenced by dietary lysine. Poultry Science, v.69, p.702-709, 1990.

OLOMU, J.M.; OFFIONG, S.A. The effects of different protein and energy levels and time of change form starter to finisher ration on the performance of broiler chicken in the tropics. Poultry Science, v.59, p.828-835, 1980.

PACK, M. Proteína ideal para frangos de corte. Conceitos e posição atual. In: CONFERÊNCIA APINCO DE CIÊNCIA E TECNOLOGIA AVÍCOLAS, 1995, Curitiba. Anais... Curitiba: Fundação Apinco de Ciência e Tecnologia Avícolas, 1995. p.95-110.

PARSONS, C.M.; BAKER, D.H. The concept and use of ideal proteins in feeding of nonruminants. In: REUNIÃO ANUAL DA SOCIEDADE BRASILEIRA DE ZOOTECNIA, 31. 1994, Maringá. Anais... Maringá: Sociedade Brasileira de Zootecnia, 1994. p.128.

RHODIMET feed formulation guide. 6.ed. France: Rhône-Poulenc Animal Nutrition, 1993. 39p.

ROSTAGNO, H.S.; ALBINO, L.F.T.; DONZELE, J.L. et al. Tabelas brasileiras para aves e suínos. Composição de alimentos e exigências nutricionais. Viçosa, MG: Universidade Federal de Viçosa, 2000. 141p.

ROSTAGNO, H.S.;BARBARINOJR., P.;BARBOZA, W.A. Exigências nutricionais das aves determinadas no Brasil. In: SIMPÓSIO INTERNACIONAL SOBRE EXIGÊNCIAS NUTRICIONAIS DE AVES E SUÍNOS, 1996, Viçosa, MG. Anais... Viçosa, MG: Universidade Federal de Viçosa, 1996. p.361.

SCHEUERMANN, G.N.; MAIER, J.C.; BELLAVER, C. et al. Exigência de lisina para frangos de corte na fase de 21 a 42 dias de idade. In: REUNIÃO ANUAL DA SOCIEDADE BRASILEIRA DE ZOOTECNIA, 30., Rio de Janeiro. Anais... Rio de Janeiro: Sociedade Brasileira de Zootecnia, 1993. p.314.

SIBBALD, J.R.; WOLYNETZ, M.S. Effects of dietary lysine and feed intake on energy utilization and tissue synthesis by broiler chicks. Poultry Science, v.65, p.98-105, 1986.

SMITH, M.O. Parts yield of broilers reared under cycling high temperatures. Poultry Science, v.72, p.146-150,1993.

SUMMERS, J.D.; LEESON, S.; SPRATT, D. Yield and compositon of edible meat from male broilers as influenced by dietary protein level and amino acid supplementation. Canadian Journal of Animal Science, v.68, p.241-248, 1988.

UNIVERSIDADE FEDERAL DE VIÇOSA - UFV. Manual de Utilização do Programa SAEG (Sistema para Análises Estatísticas 8.0). Viçosa, MG: UFV, 1999. 141p.

Recebido em: 17/08/04 Aceito em: 28/02/05 